\title{
ANALISIS PENDIDIKAN KARAKTER NILAI KASIH SAYANG \\ PADA NOVEL PADANG BULAN KARYA ANDREA HIRATA
}

\author{
Fajriniski $^{1}$, Erlina Zahar $^{2}$, Harbeng Masni ${ }^{3}$ \\ Program Studi Pendidikan Bahasa dan Sastra Indonesia, \\ Fakultas Keguruan dan Ilmu Pendidikan, Universitas Batanghari, \\ Jambi \\ fajriniski@gmail.com \\ erlina_zahar@yahoo.co.id \\ harbeng.masni@yahoo.com
}

\begin{abstract}
The purpose of this research is to describe the analysis result of educational character in affection values which are found in the novel Padang Bulan Karya Andrea Hirata. Pthis research is qualitative descriptive. The primary data is taken from the quotes that has affection values in educational character. The data is collected by using libarary technique and documentation technique which focused on educational character aspects in the novel Padang Bulan by Andrea Hirata. The data are analyzed by applying technique of analysis and description.
\end{abstract}

Kata Kunci: analysis, educational character, novel

\footnotetext{
${ }^{1}$ Mahasiswa Program Studi Pendidikan Bahasa dan Sastra Indonesia, Fakultas Keguruan dan Ilmu Pendidikan, Universitas Universitas Batanghari, Jambi

${ }^{2}$ Dosen Program Studi Pendidikan Bahasa dan Sastra Indonesia, Fakultas Keguruan dan Ilmu Pendidikan, Universitas Universitas Batanghari, Jambi

${ }^{3}$ Dosen Program Studi Pendidikan Bahasa dan Sastra Indonesia, Fakultas Keguruan dan Ilmu Pendidikan, Universitas Universitas Batanghari, Jambi
} 


\section{PENDAHULUAN}

Karya sastra tercipta berkat adanya pengalaman batin pengarang berupa peristiwa atau problem dunia yang menarik. problema kehidupan memunculkan gagasan imajinasi yang dituangkan dalam bentuk tulisan. Karya sastra akan menyumbangkan tata nilai figur serta tatanan tuntutan bagi masyarakat. Hal ini merupakan ikatan timbal balik antara karya sastra dengan masyarakat. Walaupun karya sastra berupa fiksi, namun pada kenyataannya sastra juga mampu memberikan manfaat yang berupa nilai-nilai moral bagi pembacanya.

Karya sastra memiliki beberapa jenis di antaranya drama, puisi, dan prosa. Jenis prosa diantaranya novel. Novel merupakan karangan prosa yang panjang mengandung rangkaian cerita kehidupan seseorang dengan orang di sekelilingnya dengan menonjolkan watak dan sifat setiap pelaku. Terciptanya sebuah novel pada dasarnya merupakan reaksi tehadap suatu keadaan. Novel merupakan gambaran kehidupan masyarakat yang mengandung nilai tersendiri. Dewasa ini novel sudah merupakan kebutuan manusia. Hal ini terlihat dari menjamurnya pertumbuhan novel dalam kehidupan masyarakat. Novel yang cukup membooming. Adalah novel Padang Bulan Karya Andrea Hirata.

Novel Padang Bulan Karya Andrea Hirata merupakan novel yang laris di pasaran. Novel Padang Bulan karya Andrea Hirata terdiri dari 254 halaman. Novel ini menyuguhkan suatu kisah yang menarik. Cetakan pertama saja buku ini telah banyak diminati oleh para pembaca atau penggemar novel.

Sepintas bila di baca novel ini mengedepankan tentang karakter manusia. Penulis memilih novel Padang
Bulan karya Andrea Hirata dikarenakan novel tersebut menjadi salah satu Best Seller di Indonesia. Selain itu, novel tersebut juga memuat nilai-nilai yang berkaitan dengan pendidikan karakter. Maka dari itu penulis tertarik untuk menjadikan novel ini sebagai objek penelitian.

Pendidikan karakter yang tergambar di dalam novel Padang Bulan akan sangat asik untuk disimak atau diapresiasi. Pendidikan karakter kini memang menjadi isu utama pendidikan. Selain menjadi bagian dari proses pembentukan ahlak anak bangsa, pendidikan karakter ini pun diharapkan mampu menjadi pondasi utama dalam meningkatkan derajat dan martabat bangsa Indonesia. Dengan menyadari bahwa karakter adalah sesuatu yang sangat sulit diubah, maka tidak ada pilihan lain bagi orang tua untuk membentuk karakter anak sejak usia dini. Orang tua akan menjadi pihak pertama yang kecewa jika karakter yang dibentuk oleh orang lain itu ternyata adalah karakter buruk. Dalam upaya menyusun pendidikan karakter tersebut maka dibuatlah berbagai perwujudan pendidikan karakter.

Peneliti memilih analisis nilainilai karakter dikarenakan analisis tersebut memiliki arti yang sangat penting dalam dunia pendidikan. Karena nilai moral menyangkut baik buruknya akhlak seseorang. Ditemukan dalam kasus seorang siswi SMP bernama Yuyun yang diperkosa dan di bunuh oleh tersangka bernama Zainal alias Bos di Curup Provinsi Bengkulu. Dari kasus ini jelas terliat bahwa menurunnya nilai karakter terhadap remaja maupun anak usia dini.

Dalam penelitian ini, peneliti hanya fokus pada satu permasalahan, yakni aspek kasih sayang dalam 
pendidikan karakter pada novel Padang Bulan Karya Andrea Hirata.

Adapun tujuan penelitian ini ialah, untuk mengetahui dan mendeskripsikan pendidikan karakter dalam novel Padang Bulan Karya Andrea Hirata.

Pendidikan merupakan sarana bagi masyarakat dalam melakukan pengajaran dan pelatihan untuk menjadi individu yang memiliki keterampilan dan pengetahuan. "Pendidikan senantiasa berkaitan dengan dimensi sosialitas manusia. Manusia sejak kelahirannya telah membutuhkan kehadiran orang lain dalam menopang hidupnya" (Aqib 2011: 38). Melalui pendidikan, manusia dapat saling bersosialisasi dan saling membantu dalam mencari pengetahuan.

Pendidikan merupakan tempat bagi anak-anak untuk menuju kedewasaan. Menurut M.J. Langeveld (dalam Elmubarok, 2007: 2) "Pendidikan adalah memberi pertolongan secara sadar dan sengaja kepada seorang anak (yang belum dewasa) dalam pertumbuhannya menuju kedewasaan, dalam arti dapat berdiri dan bertanggung jawab susila atas tindakan-tindakannya menurut pilihannya sendiri". Melalui pendidikan, seorang anak yang dikatakan belum dewasa dapat menjadikan dirinya bersikap dewasa.

Berdasarkan beberapa pendapat pakar di atas, maka dapat disimpulkan bahwa pendidikan adalah sarana bagi seseorang untuk menjadikan dirinya menjadi pribadi yang baik dan bersikap dewasa. Melalui pendidikan yang baik, akan tercipta karakter yang baik pula.

Karakter mencerminkan sifat alami seseorang dalam merespon situasi secara normal serta membedakan dengan individu yang lain. "Karakter adalah watak, tabiat, akhlak, atau kepribadian seseorang yang terbentuk dari hasil internalisasi sebagai kebijakan (virteus), yang diyakini, dan digunakan sebagai landasan cara pandang, berpikir, bersikap, dan bertindak" (Kemendiknas dalam purba, 2010: 36). Karakter setiap individu merupakan landasan dalam berpikir, bertindak dalam kehidupan sehari-hari.

Karakter merupakan sifat kejiwaan manusia. "Karakter adalah seperangkat sifat-sifat yang selalu dikagumi sebagai tanda-tanda kebaikan, kebijakan, dan kematangan moral sesorang" (Zuchi dalam Adisusilo, 2011: 11). Karakter setiap orang beragam bentuknya, ada yang berkarakter baik dan ada pula berkarakter buruk. Individu yang berkarakter baik biasanya moralnya sudah terlihat dalam berperilaku dalam masyarakat.

Berdasarakan uraian tentang pendidikan dan karakter di atas, dirumuskan pengertian pendidikan karakter. Menurut Lickona (dalam Wibowo, 2013: 38) "Pendidikan karakter adalah usaha yang disengaja untuk mengembangkan karakter yang baik berdasarkan nilai-nilai inti yang baik untuk individu dan baik untuk masyarakat". Secara singkat, pendidikan karakter bisa diartikan sebagai sebuah bantuan sosial agar individu itu dapat bertumbuh dalam menghayati kebebasannya dalam hidup bersama dengan orang lain dalam dunia.

Karakter merupakan perilaku manusia berhubungan dengan Tuhan Yang Maha Esa, diri sendiri, sesama manusia, lingkungan, dan kebangsaan yang terwujud dalam pikiran, sikap, perasaan, perkataan, dan perbuatan berdasarkan norma-norma agama, hukum, tata karma, budaya dan adat istiadat. Menurut Nashir ada tiga belas perwujudan karakter yang teridentifikasi yakni nilai jujur, berani, amanah, adil, bijaksana, tanggung jawab, disiplin, mandiri, malu, kasih sayang, indah, toleran, dan cinta bangsa (Nashir, 2011: 71-95). 
Adapun aspek yang terdapat pada pendidikan karakter ialah aspek kasih sayang. Kasih sayang merupakan perasaan suka, simpati, dan menyayangi terhadap sesuatu dengan sepenuh hati. "Kasih sayang adalah bagian hidup manusia yang paling penting dan utama dalam hidup manusia, kendati presepsi tentang kasih sayang antar satu orang dengan orang sering berbeda-beda" (Nashir,2013:90). Setiap manusia selalu memiliki kasih sayang terhadap sesuatu yang dianggap penting dan utama dalam hidupnya.

Menurut Siswantoro (2010:50)

peranan penelitian sastra dalam pendekatan struktural memiliki ciri-ciri meliputi:

1. Berpikir secara deduktif, adapun proses berfikir rasional adalah berfikir deduktif.

2. Evaluatif berarti memberi penilaian (judgetment) terhadap karya yang diteliti.

3. Intrinsik ciri lain penelitian dengan analisi struktural adalah fokus analisis tercurah kepada unsur-unsur pembangun struktur, yaitu unsur-unsur internal.

4. Kasuistik, penelitian sastra dengan fokus kepada analisis struktural dapat dikategorikan kepada studi kasus.

5. Sinkronik, penelitian dengan pendekatan struktural bersfat sinkronis" (Siswantoro, 2010: 57).

Peranan analisis struktural sangat penting dalam penelitian sastra. "Analisis struktural tidak saja mampu mengungkapkan makna-makna yang ada dalam simbol atau simbol-simbol yang ada di masyarakat, akan tetapi juga dapat mengungkapkan logika-logika yang ada di balik makna tersebut" (Rafiek, 2010: 76).

Langkah-langkah struktural menurut Levi-Strauss (dalam Rafiek, 2010: 75) meliputi:
1. Membaca keseluruhan cerita terlebih dahulu. Dari tahap ini diperoleh data tentang pengetahuan dan kesan cerita, tokoh-tokohnya, tentang berbagai tindakan yang mereka lakukan.

2. Apabila terlalu panjang, cerita tersebut dapat dibagi menjadi beberapa episode. maka pembacaan ulang tentang cerita-cerita itu dapat dilakukan dengan lebih saksama lagi untuk memperoleh pengetahuan yang jelas yang dapat digunakan sebagai dasar dalam analisis ini.

3. Setiap episode mengandung deskripsi tentang tindakan atau peristiwa yang dialami tokoh-tokoh dalam cerita.

4. Memperhatikan adanya relasi-relasi atau kalimat-kalimat yang menunjukan hubungan-hubungan tertentu antar elemen dalam suatu cerita.

5. Elemen-elemen disusun secara diakronis dan singkronis atau mengikuti sumbu sintagmatik dan paradgmatik. Makna elemen mitos tergantung kepada relasi sintagmatis dan paradigmatisnya dengan elemenelemen yang lain.

6. Mencoba menarik hubungan relasi anatarelemen di dalam suatu cerita secara keseluruhan.

7. Menarik kesimpulan akhir dengan mencoba memaknakan cerita-cerita internal di atas dengan kesimpulankesimpulan referensial atau kontekstual dimana cerita itu berada dan mencobanya menarik sebuah makna yang utuh secara umum.

Berdasarkan uraian di atas, dapat disimpulkan bahwa pendekatan struktural merupakan suatu pendekatan yang digunakan untuk membangun sebuah karya sastra secara kompleks dan terarah. Langkah-langkah menganalisis di atas, penulis jadikan langkah menganalisis pendidikan karakter pada novel Padang Bulan karya Andrea Hirata. 


\section{METODE PENELITIAN}

Jenis penelitian ini deskriptif kualitatif. "Penelitian kualitatif akan melihat segala sesuatu yang terdapat pada abjeknya masih bersifat umum, setelah itu akan terdapat tahap orientasi dan deskripsi” (Sugiyono, 2013: 19). Kualitatif merupakan penelitian yang alamiah dan menggunakan berbagai metode sebagai pendukung dalam penelitian yang sedang dilakukan oleh peneliti. "Deskriptif adalah data yang dikumpulkan berupa kata-kata, gambar dan bukan angka-angka" (Moleong, (2010: 11).

Hasil penelitian ini berupa data yang berisi kutipan-kutipan yang memerikan gambaran penyajian laporan. Kutipan-kutipan diperoleh dari novel yang diteliti. Pada penelitian ini penulis menganalisis pendidikan karakter dalam novel padang bulan karya Andrea Hirata.

Penelitian deskriptif bertujuan untuk mendiskripsikan, mencatat, menganalisis dan menginterprestasikan kondisi yang ada. Oleh sebab itu, pemikiran dan penafsiran terhadap data atau fakta-fakta yang ditemukan sangat diperlukan. Penelitian yang menggunakan metode deskriptif ini tidak terbatas sampai pengumpulan data, penyusunan data, tetapi juga meliputi analisis tentang arti dari data tersebut.

Data dalam penelitian ini dibagi menjadi dua data, yakni data primer dan data sekunder. Data primer merupakan data utama yang sangat penting dalam sebuah penelitian. "Data primer adalah data utama, yaitu data yang diseleksi atau diperoleh langsung dari sumbernya tanpa perantara" (Siswantoro 2010: 70). Data primer penelitian ini diambil dari novel Padang Bulan karya Andrea Hirata berupa kutipan-kutipan yang berisikan tentang pendidikan karakter. Data Sekunder merupakan data yang diperoleh secara tidak langsung atau melalui perantara. "Data sekunder adalah data yang tetap berstandar kepada kategori atau prameter yang menjadi rujukan" (Siswantoro, 2010: 71). Data sekunder dalam penelitian ini berupa kutipankutipan yang bersumber dari buku-buku tentang pendidikan karakter, buku tentang sastra, buku metode penelitian sastra, dan buku-buku yang digunakan sebagi penunjang dalam penelitian ini.

Dalam hal ini, peneliti menggunakan metode analisis isi teks dengan memaparkan dalam bentuk penggambaran terhadap masing-masing data yang terkumpul. Kemudian diperkuat dengan berbagai kutipan yang terdapat dalam novel Padang Bulan karya Andrea Hirata. Dalam penelitian ini, data berupa kutipan-kutipan yang terdapat dalam novel. Langkah-langkah yang dilakukan peneliti dalam menganalisis data yakni sebagai berikut:

1. Data yang sudah diklasifikasikan pada teknik pengumpulan data di atas, kemudian dikelompokkan berdasarkan aspek-aspek penelitian yang diteliti.

2. Data yang sudah dikelompokkan berdasarkan aspek-aspek yang diteliti sesuai dengan jenis selanjutnya dimasukkan ke dalam tabel tabulasi data.

3. Setelah ditabulasi, langkah selanjutnya yaitu menginterpretasikan data yang sudah ditabulasikan sesuai dengan kerangka teori.

4. Setelah diinterprestasikan, data dianalisis mengunakan metode deskriptif.

5. Merumuskan kesimpulan dari langkah-langkah penelitian yang telah dilakukan.

\section{HASIL DAN PEMBAHASAN}

Berdasarkan hasil analisis yang telah dilakukan mengenai analisis nilainilai kasih sayang dalam pendidikan karakter pada novel Padang Bulan karya 
Andrea Hirata, maka penulis menemukan sebanyak 12 kutipan. Dari 12 aspek tersebut terdapat dalam novel Padang Bulan karya Andrea Hirata dalam kehidupan sehari-hari.

\section{Analisis Aspek Kasih Sayang yang Terdapat dalam Novel Padang Bulan Karya Andrea Hirata}

Kasih sayang merupakan sesuatu yang di anggap penting oleh manusia. Melalui kasih sayang, seorang dapat mengungkapkan perasaan suka, simpati, dan menyayangi sesuatu dengan sepenuh hati. Setiap orang memiliki presepsi berbeda-beda mengenai sikap kasih sayang antara orang satu dengan orang yang lain. Dengan demikian, sangatlah penting menanamkan sikap kasih sayang terhadap sesama manusia dan alam agar terjalin hidup yang harmonis.

\section{Syalimah gembira karena suaminya mengatakan akan} memberinya hadiah. Syalimah tak tahan. "Aih, janganlah bersenda, Pak Cik. (Padang Bulan: 1).

Kutipan ini menggambarkan karakter kasih sayang yang dimiliki tokoh Syalimah, ini digambarkan sikap gembira Syalimah terhadap perkataan suaminya yang hendak memberi hadiah. Dari kutipan tersebut. terlihat tokoh Syalimah memiliki perasaan suka, simpati, dan menyayangi sesuatu dengan sepenuh hati. Syalimah yang memiliki karakter kasih sayang terhadap suaminya dianggap penting dan utama di dalam hidupnya.

\section{Zamzami tahu anaknya pasti tidak} bisa tidur karena terus-terusan membayangi kamus itu. Maka tanpa ambil tempo, ia segera mengajak Sirun ke Tanjong Pandan. Mereka bersepeda hamper beratus kilometer. (Padang Bulan: 14).

Kutipan ini menggambarkan karakter kasih sayang yang dimiliki tokoh Zamzami, ini digambarkan perjuangan Zamzami bersepeda hampir beratus kilometer untuk membeli kamus untuk putrinya. Dari kutipan tersebut, terlihat tokoh Zamzami memiliki perasaan suka, simpati, dan menyayangi sesuatu dengan sepenuh hati.

\section{Sejak kemarin Syalimah} menyiapkan keberangkatan Enong ke Tanjung Pandan, tapi ia tak sanggup. Jika melihat tas yang akan di bawa putrinya, air matanya berlinang. Satusatunya yang bisa ia lakukan hanyalah menguatkan hati anaknya dan itu tak bisa ia lakukan jika ia sendiri tampak kalah atas situasi yang menjepit mereka. (Padang Bulan: 35).

Kutipan ini menggambarkan karakter kasih sayang yang dimiliki tokoh Syalimah, hal tersebut digambarkan dengan kesedihan Syalimah yang tak kuasa menahan tangis setiap kali melihat tas putrinya yang akan di bawa ke kota. Dari kutipan ini, terlihat tokoh Syalimah memiliki perasaan simpati, dan menyayangi sesuatu dengan sepenuh hati. Syalimah yang memiliki karakter kasih sayang terhadap anaknya dianggap penting dan utama di dalam hidupnya.

\section{Di lapangan telah menunggu}

Nuri, Ilham, Nizam dan Naila.. merekalah sahabat terdekat Enong, sesama penggermar pelajaran bahasa Inggris. Ilham hanya diam. Ketika akan berpisah, keduanya merasakan kehilangan juga dengan cara yang tak dapat dijelaskan. Anak-anak itu bergandengan tangan dan menangis. (Padang Bulan: 36). 
Kutipan tersebut menggambarkan karakter kasih sayang yang dimiliki teman-teman Enong, hal tersebut digambarkan dengan kesedihan Nuri, Nizam, dan Naila yang menangis ketika Enong hendak berpamitan, merka saling bergandengan tangan sambil menangis. Dari kutipan ini terlihat teman-teman Enong memiliki perasaan simpati, dan menyayangi Enong dengan sepenuh hati.

Syalimah tersedu sedan. Ia bersimpu di samping Zamzami yang telah mati. Ia mengangkat kepala suaminya ke atas pangkuannya. Kepala itu terkulai seperti ingin bersandar. (Padang Bulan: 9).

Kutipan tersebut menggambarkan karakter kasih sayang yang dimiliki tokoh Syalimah, hal tersebut digambarkan dengan kesedihan Syalimah yang tak kuasa menahan tangis melihat sang suami yang telah meninggalkan dirinya dan anak-anaknya untuk selamanya. Dari kutipan ini terlihat tokoh Syalimah memiliki perasaan simpati, dan menyayangi suami dan anaknya dengan sepenuh hati.

"Pak Cik, aku hanya kenal cinta sekali saja. Sekali saja. Hanya pada Zamzami . itulah cinta pertamaku, yang akan ku bawa sampai mati. Syalimah sekarang menjadi perempuan tua yang tetap hidup dengan satu cinta untuk seorang lelaki meski lelaki itu sudah tidak ada. (Padang Bulan: 102).

Kutipan tersebut menggambarkan karakter kasih sayang yang dimiliki tokoh Syalimah, ini digambarkan dengan kesedihan Syalimah yang tak kehilangan suaminya, ia tak ingin menikah lagi karena Zamzami adalah cinta pertamanya dan akan di bawah hingga mati kelak. Dari kutipan ini terlihat tokoh Syalimah memiliki perasaan simpati, dan menyayangi suaminya dengan sepenuh hati.

\section{Meskipun Detektif sering} dimarahi ibunya sebenarnya keduanya sangat dekat. Mungkin karena ia anak bungsu. Sebelum masuk dalam bus tadi, Detektif mencium tangan ibu sambil berlinangan air mata. Lalu mereka berpelukan lama sekali. Sang ibu, melepas anaknya sepertri takkan melihatnya lagi. (Padang Bulan: 157).

Kutipan ini menggambarkan karakter kasih sayang yang dimiliki tokoh Detektif M. Nur, ini digambarkan dengan kesedihannya yang akan pergi meninggalkan ibunya yang diringi dengan derai air mata. Dari kutipan tersebut, terlihat tokoh Detektif M. Nur memiliki perasaan simpati, dan menyayangi sesuatu dengan sepenuh hati.

Dari dalam bus Detektif memandangi ibunya. Lalu, agaknya seperti film India, ia turun dan memeluk ibunya lagi. Keduanya terisak. Sungguh sebuah pemandangan yang memilukan. (Padang Bulan: 157).

Kutipan ini menggambarkan karakter kasih sayang yang dimiliki tokoh Detektif M. Nur, ini digambarkan dengan kesedihannya yang akan pergi meninggalkan ibunya yang diringi dengan derai air mata dan ia turun lagi dari bus memeluk ibunya. Dari kutipan ini terlihat tokoh Detektif M. Nur memiliki perasaan simpati, dan menyayangi ibunya dengan sepenuh hati.

Dalam ikatan kertas lain, kutemukan surat ini: kalau rindu, ucapkan namaku lima puluh kali. Nanti tak rindu lagi. Ku pejamkan mataku ku sebut nama A Ling lima puluh kali. Ku buka mata $k u$ lihat sekeliling, lampu 
padam, malam diam, aku masih rindu. (Padang Bulan: 285).

Kutipan ini menggambarkan karakter kasih sayang yang dimiliki tokoh aku, ini digambarkan dengan kerinduannya pada wanita pujaan hatinya. Dari kutipan tersebut terlihat tokoh aku memiliki perasaan suka, simpati, dan menyayangi pujaan hatinya dengan sepenuh hati.

Ku lihat ia mengusap air mata dengan lengannya. Sejak kecil aku tak mampu berpaling pada perempuan lain.

Aku mengenggam jemariku sendiri yang gemetar. Betapa aku sayang pada orang itu. (Padang Bulan: 291).

Kutipan tersebut menggambarkan karakter kasih sayang yang dimiliki tokoh aku. Hal tersebut digambarkan melalui tokoh aku yang tak pernah berpaling pada perempuan lain, ketika melihat A ling menangis ia tak tega. Dari kutipan ini terlihat tokoh aku memiliki perasaan suka, simpati, dan menyayangi A ling dengan sepenuh hati.

Aku baru saja melihat $A$ Ling tadi sore, tapi rindu padanya tak tertahankan. Aku sering menjumpainya berates-ratus kali, namun pertemuan esok membuatku berdebar-debar seperti aku akan menemuinya pertama kali. (Padang Bulan: 293).

Kutipan tersebut menggambarkan karakter kasih sayang yang dimiliki tokoh aku. Hal tersebut digambarkan dengan kerinduan tokoh aku kepada A ling yang barus saja dilihat, setiap pertemuan membuat dadanya berdebardebar seperti orang yang baru pertama kali bertemu. Dari kutipan ini terlihat tokoh aku memiliki perasaan suka, simpati, dan menyayangi A ling dengan sepenuh hati.

\section{SIMPULAN}

Berdasarkan hasil analisis diperoleh kesimpulan bahwa terdapat 12 aspek kasih sayang dalam nilai-nilai pendidikan karakter pada novel Padang Bulan karya Andrea Hirata.

Kasih sayang merupakan sesuatu yang dianggap penting oleh manusia. Melalui kasih sayang, seseorang dapat mengungkapkan perasaan suka, simpati, dan menyayangi sesuatu/seseorang dengan sepenuh hati. Setiap orang memiliki presepsi berbeda-beda mengenai sikap kasih sayang antara orang satu dengan orang yang lain. Dengan demikian sangatlah penting menanamkan sikap kasih sayang terhadap sesama manusia dan alam agar terjalin hidup yang harmonis. Analisis aspek nilai kasih sayang terdapat sebanyak 12 kutipan.

\section{DAFTAR PUSTAKA}

Adisusilo, Sutarjo. (2011). Pembelajaran Nilai-nilai Karakter Kontruktivisme dan VCT sebagai Inovasi Pendekatan Pembelajaran Afektif. Jakarta: PT Grafindo Persada.

Aqib, Zainal dan Rujak. (2011). Panduan Aplikasi Pendidikan Karakter. Jakarta: Gaung Persada Press.

Moleong, Lexy. (2010). Metodologi Penelitian Kualitatif. Jakarta: Remaja Rosdakaruya.

Nashir. (2011). Pendidikan Karakter Berbasis Agama dan Budaya. Yogyakarta: Multi Presindo.

Rafiek, M. (2010). Teori Sastra: Kajian Teori dan praktik. Bandung: Ritika Adiyatama.

Siswantoro. (2010). Metode Penelitian Sastra Analisis Struktur Puisi. Yogyakarta: Pustaka Pelajar. 
Sugiyono. (2009). Metode Penelitian

Kuantitatif, Kualiatif, $R \& d$.

Bandung: Alfabeta.

Wibowo. (2013). Pendidikan Karakter di

Pergguruan Tinggi. Yogyakarta:

Pustaka Pelajar.

Analisis Pendidikan Karakter Nilai Kasih Sayang pada Novel Padang Bulan

Karya Andrea Hirata 